\section{ISLET-CELL TUMOUR OF THE PANCREAS}

BY

\author{
D. D. WEBSTER, M.B., B.S., D.P.M. \\ Senior Registrar, St. Luke's Hospital, Middlesbrough
}

AND

\section{A. N. BLADES, M.B., B.S. Pathologist, Central Clinical Laboratory, Middlesbrough}

We should like to put on record another case of this disorder, which presented an unusual feature-the coincidence of hypoglycaemic attacks with the menstrual periods.

\section{Case History}

The patient, a single typist aged 20 , had no significant previous medical history. In October, 1950, on the first day of the period, after rising in the morning, she had an episode lasting about an hour in which she felt "dazed." Her mother described her behaviour as "trance-like and automatic," and she was slow to respond. She had difficulty in eating breakfast, and was found in the kitchen going through the motions of bread-cutting with empty hands. Nothing else abnormal was noticed, and the trouble cleared during the day.

In November, again at the time of the menses, a similar episode took place, her mother finding it difficult to get her roused and off to work. In December, when the symptoms occurred again, she was taken to her doctor, who found no abnormality and considered that it was either petit mal or a neurosis.

In January, 1951, on the first day of the menses, she had an episode in the late evening in which she flung her arms about in a trance and knocked things over. Her father observed that she perspired freely. By the time the doctor arrived, an hour later, she was normal again. In February a similar "dreamy state" recurred. In between these attacks she lived a normal life, continuing with work and social activities.

In March, on a Saturday at the time when she was due for her period, her mother found that she had not got out of bed after being called. She seemed to be in a "comalike" state and was unable to do anything for herself. This lasted for a matter of hours, but by early afternoon she improved, her confusion cleared, and she went to bed normally. During the night she was extremely restless and "flung her arms about continuously."

The following day, Sunday, she was "semi-stuporous," but became more lucid towards the evening. During these two days she ate normal meals except for breakfast. That night she was again restless, and the mother reported that occasional "muscular spasms" occurred, when she clenched her hands and stiffened her legs; but her parents managed to feed her with rum and hot milk, which brought about an improvement in her condition, and in the early morning she emerged from the stupor and was perfectly orientated, recognizing her doctor without difficulty and chatting brightly with him.

She remained well all that day, Monday, and in the evening entertained a friend to supper. She went to bed at 10 p.m., but during the night the restlessness recurred with purposeless movements of her arms and legs, and she was not responsive to normal stimuli. Her respirations were rapid and stertorous and her temperature seemed to be raised.

She was admitted to hospital at 2.30 p.m. on Tuesday, March 13. On examination she was in a deep coma, temperature $101^{\circ}$ F. $\left(38.3^{\circ}\right.$ C.), respirations 30 , and pulse 64. Tendon reflexes were increased, abdominals absent, plantars extensor. An electroencephalogram showed a diffuse disturbance of low frequency and high voltage indicative of a generalized metabolic disorder. Bloodsugar estimation gave $64 \mathrm{mg}$. per $100 \mathrm{ml}$.

She was given glucose per rectum and later intravenously, but without response. She died the following night, 33 hours after admission, without recovering consciousness. The blood sugar shortly before death was $20 \mathrm{mg}$. per $100 \mathrm{ml}$.

\section{Pathological Findings}

At necropsy the pituitary gland was enlarged to one and a half times the normal size, projecting upwards round the stalk, and was golden yellow on section. Histologically the enlargement was in the anterior lobe, in which conspicuous blocks of eosinophil cells were seen. The proportion of these cells was high, but was not significantly beyond normal limits. The thyroid was inactive, with much colloid.

The pancreas contained a rounded dark-red, soft, solid tumour $\frac{1}{2}$ in. $(1.25 \mathrm{~cm}$.) across projecting forwards from the gland at the junction of the left and middle thirds. Histologically this consisted of solid islet tissue and was devoid of capsule; it was invading blood vessels, but in view of the remarks of Frantz (1940) it is not possible to maintain that it was malignant, as no metastases were found. The suprarenals, thymus, and ovaries were normal. Apart from oedema of the lungs, no other abnormality was found.

\section{Discussion}

Over 400 cases of islet-cell tumour of the pancreas are now on record (Howard, Moss, and Rhoads, 1950). The following particular points are of interest in the present case.

(1) The comparatively short time between clinical onset and death-just under six months.

(2) The occurrence of the symptoms only at the time of onset of menstruation or the day before. Taken together with the enlargement of the pituitary, this suggests that the activity of the tumour is affected in some way by the hormones of the pituitary-ovarian -complex. We do not feel competent to speculate on the nature of this interconnexion, but a search of the literature shows that at least four other cases are on record in which hypoglycaemic symptoms coincided with the onset of the period (Whipple and Frantz, 1935 ( 2 cases) ; Mitchell et al., 1938 ; Howard, Moss, and Rhoads, 1950). It may be no more than an expression of the alteration of the metabolic rate which occurs at that time, but if this is so it is difficult to see why symptoms are not provoked by exertion or hunger, etc., occurring in the normal course of events at other times. This periodicity can mislead so far as the differential diagnosis from epilepsy is concerned, because, as is well known, this disorder may show itself only at the time of menstruation.

(3) As Duras (1951) points out, the blood-sugar level is no criterion for diagnosis. In this instance the blood sugar on admission was $64 \mathrm{mg}$. per $100 \mathrm{ml}$., although the patient was in deep coma. Similar blood-sugar levels, and higher ones, are often found in "prolonged coma" following insulin treatment for schizophrenia, and in these cases it would seem that the prolonged hypoglycaemia causes a cessation of cerebral metabolic processes, since even massive doses of glucose intravenously may produce no effect; it is known, however, that if this glucose is followed by a small dose of insulin the successful termination of "prolonged coma" can sometimes be brought about, and it has therefore been suggested that the second dose of insulin acts as a stimulus to cerebral metabolism. We suggest, therefore, that in the treatment of coma due to pancreatic hypoglycaemia, or of suspected cases, a normal blood sugar should not be allowed to negative the diagnosis, and that after glucose has been given intravenously, without response, a small dose of insulin-for example, 5 to 10 units-might be tried. Rectal 
administration of glucose may serve as a first-aid measure, but it is now considered that absorption is very slow and incomplete (Peters and Van Slyke, 1946).

\section{Summary}

A fatal case of functioning islet-cell tumour of the pancreas in a woman of 20 is described.

The regular association of symptoms with the start of the menstrual period is noted.

Pathological findings are given, and some suggestions are made about treatment in the light of experience with insulin coma therapy in schizophrenia.

We wish to thank Professor R. A. Willis for his opinion on the pituitary gland and Dr. T. M. Cuthbert, physician superintendent, St. Luke's Hospital, for his advice and opinion on the electroencephalogram.

\section{REFERENCES}

Duras, F. P. (1951). British Medical Journal, 1, 702

Frantz, V. K. (1940). Ann. Surg 112, 161.

Howard, J. M., Moss, N. H., and Rhoads, J. B. (1950). Surg. Gynec. Obstet. 80 (Inst. Abst. Surg.) 417

Mitchell, H. L., et al. (1948). J. nerv. ment. Dis., $107,545$.

Peters, J. P., and Van Slyke, D. D. (1946). Quantitative Clinical Chemistry, London.

Whipple, A. O., and Frantz, V. K. (1935). Ann. Surg., 101, 1299.

\section{Medical Memoranda}

\section{Intra-partum Uterine Rupture}

Uterine rupture, whether in the upper or the lower segment, is one of the most serious catastrophes in obstetric practice, but it is not generally recognized that, of the two, rupture in the lower segment is much the more dangerous.

Dugger (1945) collected 105 cases of uterine rupture $(65$ died and 40 recovered) -34 were ruptures of upper-segment section scars (27 recovered and 7 died) and 71 were of lowersegment rupture (58 fatal). Watt (1950), in an analysis of 15 cases of uterine rupture occurring in the Toronto General Hospital, found 9 of the lower-segment type with 3 maternal deaths, and 6 in the upper segment with no maternal deaths. Simons (1950) described three cases of lower-segment rupture occurring in women of high parity, and all terminated fatally. Sheehan (1948), in 147 necropsies on patients dying from obstetrical shock, found 20 cases of rupture of the uterus, most of which had been undiagnosed in life. Only one of these was of the upper-segment type, all the others being lateral tears in the lower segment.

Rupture in the lower segment is at the onset extraperitoneal, except in the rare case of posterior rupture. The extraperitoneal rupture which has been given the unfortunate name of incomplete rupture-thereby implying a less serious condition than the transperitoneal rupture-may extend into the plexus of large veins situated in and around the lower segment, or into the uterine veins themselves, without producing any immediate and dramatic change in the patient's condition. The bladder may be involved at the same time. Thus rapid venous bleeding may be taking place and remain undiscovered until the patient suddenly collapses. The earliest, clue to the true state of affairs is weakening or cessation of the pains ; and recognition of its true significance is absolutely vital, and must not be confused with uterine inertia.

Examination of the patient may now reveal that the presenting part has risen from the pelvis and may be lying in the iliac fossa, and that vaginal bleeding is occurring. Both these signs, however, may be missed at this stage if the significance of the sudden cessation of labour pains is not realized. If the true state of affairs remains unrecognized, then acute circulatory deficiency soon becomes evident, and finally the peritoneum overlying the rapidly developing haematoma ruptures and acute peritoneal shock is added to acute blood loss. Furthermore, the muscle of the lower segment is unable to contract down upon the bleeding vessels, and blood continues to pour out as long as the heart can maintain a circulation. In this type of case bleeding takes place so rapidly that ordinary transfusion methods cannot supply blood at an adequate rate, and early diagnosis and laparotomy offer the only hope of saving the patient's life.

In contrast, rupture in the upper uterine segment as a rule gives a fairly clear-cut picture of the acute abdomen with intraperitoneal bleeding, but once the uterine contents have been extruded into the peritoneal cavity the uterus can and does act as its own haemostat, contracting down firmly on the bleeding vessels. In this case immediate operation is not an absolute necessity, and time can be taken for resuscitation before operation.

The following cases illustrate the above points.

\section{CASe 1}

The patient was a 38-year-old 11-gravida whose expected date of delivery was October 10, 1948. Her previous delivery was by classical caesarean section for severe antepartum haemorrhage due to placenta praevia. The operation had to be terminated rapidly owing to her poor condition, and she was advised to undergo hysterotomy and sterilization for any subsequent pregnancy, as the quality of the uterine repair was suspect. She had ignored this advice and had not attended any antenatal clinic during the present pregnancy.

At 9 a.m. on October 4 she had sudden severe abdominal pain and was admitted to hospital two hours later. On admission she was extremely collapsed, pale, clammy, and restless, with an almost imperceptible pulse and unrecordable blood pressure. The abdomen showed generalized tenderness and rigidity and the presence of free fluid. A foetal limb could be felt lying superficially under the left costal margin. There was no vaginal bleeding. A diagnosis of ruptured upper-segment scar was made, and morphine $\frac{1}{6} \mathrm{gr}$. (11 mg.) was given intravenously. Plasma transfusion was begun, followed by cross-matched blood. At 5 p.m.- that is, eight hours after rupture-the blood pressure was 76/ 40 , and laparotomy was carried out. Foetus, placenta, and blood were removed, and the uterus was found to be ruptured along the line of the previous incision, and was so firmly contracted that it was almost turned inside out. A subtotal hysterectomy was performed, and at the end of the operation the blood pressure was $92 / 60$. The patient made an uneventful recovery and was discharged on the 12th day.

\section{CAse 2}

A 4-gravida aged 35, whose expected date of delivery was April 10, 1950, had her first confinement in Norway in 1946. She was for three days in strong labour; forceps delivery and a pyrexial puerperium followed, and she was in hospital for a month after delivery. The subsequent deliveries were in a nursing-home in this country, the first being a stillborn breech, birth weight $8 \mathrm{lb}$. $5 \mathrm{oz}$. $(3.8 \mathrm{~kg}$.), after 20 hours in labour, and the second a normal vertex delivery, birth weight $7 \mathrm{lb} .6 \mathrm{oz}$. $(3.2 \mathrm{~kg}$.), after four hours in labour. At the 36th week of the present pregnancy the presentation was a breech, which was easily rotated to a vertex. There was no placental tissue palpable in the lower segment, and the true conjugate measured 4 in. $(10 \mathrm{~cm}$.). The inlet was slightly android, but the cavity and outlet were normal. These clinical findings were confirmed by $x$-ray pelvimetry. The presentation remained a vertex, and she was admitted in labour at full term.

On admission her condition was good, blood pressure being $134 / 80$ and pulse rate 80 ; pains were occurring regularly every five minutes, and the head was engaged at the brim. After a further two hours in strong labour the presenting part was entering mid-cavity with the cervix twothirds dilated. At this point the patient had a sensation 